\title{
Human Resource Copious India- in Alarming need of Workplace Spirituality
}

\author{
Shipra Agarwal, Vartika Baral, Shipra Gupta
}

\begin{abstract}
India is renowned across the globe for its rich heritage, culture and spirituality. But how far has the country been able to make productive and beneficial use of its richness, is still a very questionable subject. Since ages, India has been a leader in spirituality;it was a practice and perception that mostly the elderly people of society follow the spiritual path because the working population can't spare time from their busy and productive schedule. Attention was never given to the fact that spirituality, if rightfully practiced, can increase the productivity of an individual as well as organization many folds. With special emphasis on the Spiritual faith of Indian masses,this study isprecisely aimed at addressing the reasons and outcomes of spirituality at workplace and the ways and methods of implementing Workplace spirituality in the organizational environment. This concept oriented paper is to provide for a deep understanding as to why and how the individuals at work must practice and preach their spiritual values at work, leading to remarkable results in improvingthe overall productivity of the workforce and the organization alike. It also extends an aid for the economic issues like Brain Drain, Low GDP and increased employee turnover as an inevitable outcome of the lack of management attention towards employee wellness and their spiritual growth at work. The study helps to embrace the essence of a splendid professional life for all working individuals in the light of Workplace Spirituality, promoting peace, happiness and health in the working atmosphere within an organization, which in turn leads to greater job-satisfaction along with a better sense of job-fulfillment.
\end{abstract}

Keywords: Workplace spirituality, Work culture, Employee wellness, Productivity, Workforce, Brain Drain, Low GDP, Employee turnover, Job Satisfaction, job-fulfillment.

\section{INTRODUCTION}

The spiritual tradition in India is the oldest and the most valuable. Indian lives have always been dominated by the aim of harnessing the spirit, before achieving any temporary pleasures (worldly desires). There were many spiritual masters and literates who preached the concepts of enlightenment, karma and truth since the pre-Vedic times and believed that the knowledge of the universe was encoded in many incantations (Shlokas and mantras). The Gurukul system prevailed where the students were taught about the four stages (Ashramas) of life - Brahmacharya Ashram (student), Grihastha Ashram (married), Vanaprastha Ashram (retired) and Sannyasa Ashram (renunciate). ${ }^{[1]}$ The vast literature in the Upanishads and Puranas gave an access to the knowledge of the divine, whereas the Sanskrit scriptures like ShrimadBhagavada Gita highlighted the importance of the spiritual principles in a human's life.

Revised Manuscript Received on April 25, 2019.

Shipra Agarwal, Department of commerce, Graphic Era Deemed to be University, Dehradun, Uttarakhand, India. shipra.agg26@gmail.com

Vartika Baral, Department of commerce, Graphic Era Deemed to be University, Dehradun, Uttarakhand, India. shipra.agg26@gmail.com

Shipra Gupta, Associate Professor, Department of Commerce, Graphic Era Hill University, Dehradun, India
Apart from this, there were various ancient Indian Epics focusing on the concepts of the soul related to Karma and faith. Takshashila and Nalanda were considered the hub of education throughout the globe and were the oldest universities to have been established for educating the students in different discipline with utmost

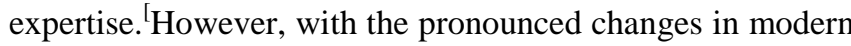
world, this Indian heritage is lost because the people today find themselves incapable of keeping up with the spiritual values bestowed to them by their culture. The detachment of a human with his inner-self and to his roots continues to deteriorate, causing an alarming situation for the country where only a few have been in instrumental reviving the nearly-dead inheritance. Shri Rabindranath Tagore (1913) followed by Shri Vidiadhar Suraj prasad Naipaul (2001) in literature, Shri Chandrasekhara Venkata Raman (1930) and Sir Subrahmanyam Chandrasekhar (1968) in physics, Sir HarGobind Khoran (1968) in physiology and medicine, Mother Teresa (1979) before Sir KailashSatyarthi (2014) for peace, Sir Amartya Sen (1998) and Sir Abhijit Vinayak Banerjee (2019) in Economic sciences, Sir Venkatraman Rama krishnan (2009) in chemistry - are the revered names of the legendary Indians who won the Noble prize in their respective domains and brought tons of glory and honor for the Nation. ${ }^{[2]}$ But exactly what made these people stand out from the crowd and distinguish themselves from the other human resources in India? Where is the difference? If we come to acknowledge and embrace the phenomenon of Workplace spirituality, we will be able to find out that these highly qualified personalities gave priority to their ethics, beliefs and morality in all spheres of life over the societal norms and preconceived notions of the community. They were able to align their spiritual values with their dreams and passion, thereby gaining the confidence to listen to the voice of their conscience and finally making it a part of their success stories. But this sense of spirituality is yet to find its true potential in India but the country still stands inadequate to nurture this essential attribute in its human resources. It curbs the nation's capacity to empower the probable legends and their struggles for success, lowers the productivity of the country and the country men, leads to mass migration for competent personnel to foreign provinces, adversely impacts the economy's competitive spirit in the global play as well as cuts off the existing opportunities and prospects for sustainable development and overall growth of the nation With the above mentioned it becomes pretty transparent that it is the final call of the hour that India must, at its earliest, adopt and imbibe Workplace Spirituality into its corporate culture so as to have an edge over other countries, meanwhile ensuring the best for its HR.

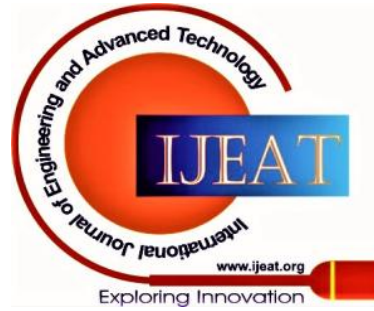




\section{Human Resource Copious India- in Alarming need of Workplace Spirituality}

\section{SPIRITUALITY}

Spirituality has ample dimensions to project itself in new found ways. It cannot be accurately put to a form of any precise definition, yet it is widely preached, practiced and perceived by the modern as well as traditional communities and is being explored in depth by the researchers. All humans conveniently divide their life into different prospects of living. The wheel of wellness projects 7 distinct dimensions of a human life, a major one being spirituality (Fig. 1). ${ }^{[3]}$ The inherent nature of a person defines his Spiritual principles, thus making Spirituality an indispensable phenomenon for the wholesome existence of humanity. 'Spirituality' comes from a Latin word 'Spiritualis', denoting the aspects of human life concerning the spirit. Hence in order to grab the essence of the spirituality, it becomes fundamental to understand the relevance of the human identity as a spirit first.

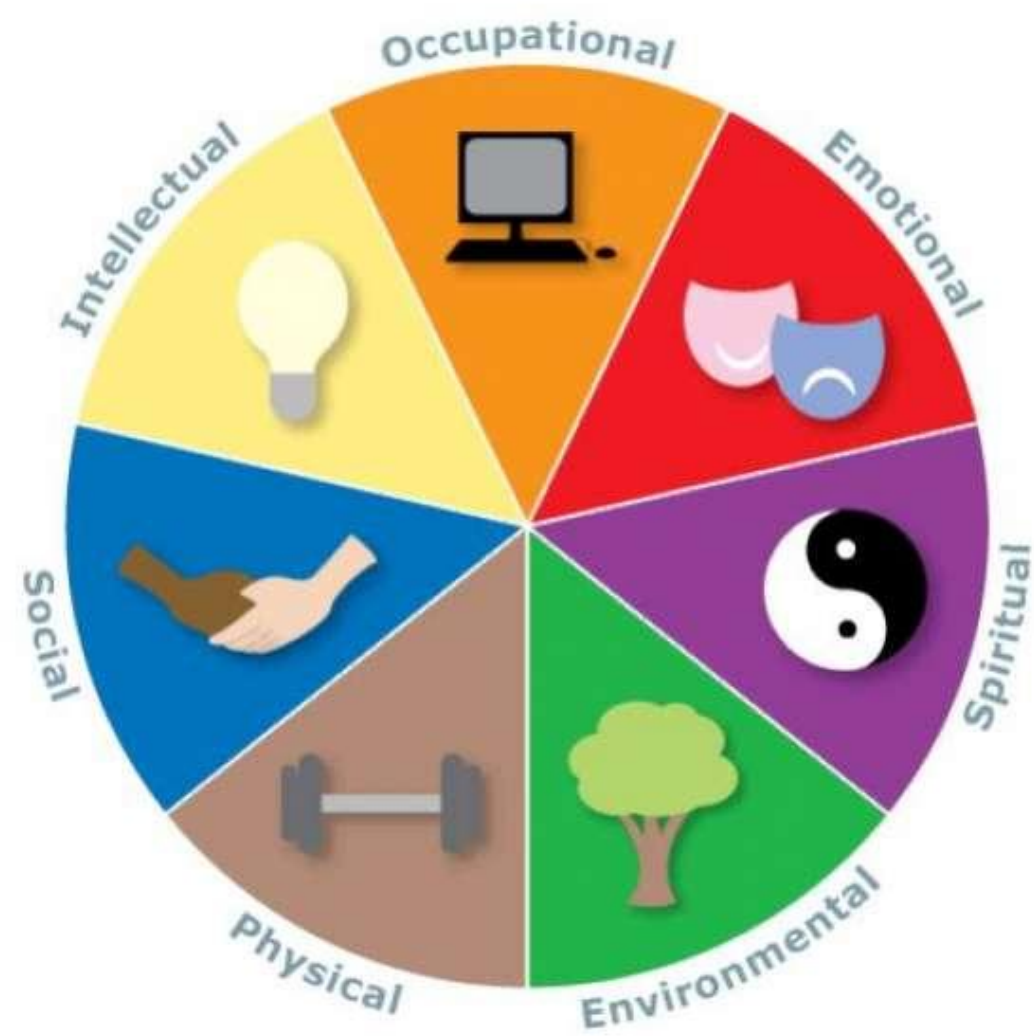

Figure 1. The 7 Dimensions of the Wheel of Wellness

The term Spirit also originates from a Latin word 'Spiritus' (meaning soul). The spirit is recognized as an eternal cosmic energy which infuses life-force into the living. This concept stands undivided for humans and animals (even plants in most religions) according to conventionally established principles. Thus in the spiritual sense, a man is not merely a body of blood and bones (mortal), rather is a spirit (immortal) with a deeper purpose and meaning for its existence as a sub-set of the great universe.

Spirituality is all about finding sense in the conduct of life and its various aspects by connecting to the higher self. It is about realizing the true nature of the soul within us and being led by the self-defined virtues and morals for inner bliss and profound satisfaction, rather than being by the shallow ways of the world and material pleasures. Spirituality focuses on embracing the bond of our spirit (cosmic energy deemed as the soul) with the supreme authority (God). Consequently Spiritual practices help in putting our five senses, mind and intellect to best use so we can embrace the potential of the Soul within us and embark on our Spiritual journey to find our connection with God (Fig. 2). ${ }^{[4]}$

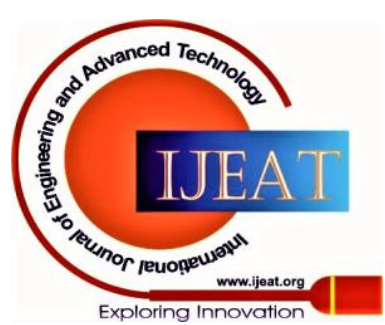




\section{Definition of spiritual practice}

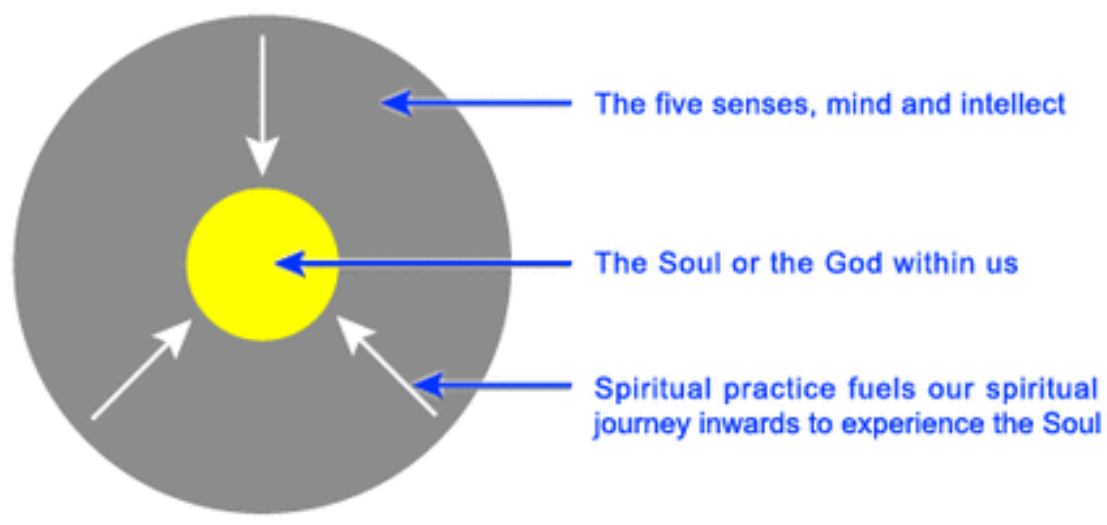

Figure 2. Definition of Spiritual Practice

\section{WORKPLACE SPIRITUALITY}

Work place spirituality was a massive movement that originally commenced in the beginning of 1920 s in United Statesand later took international grounds.For the purpose of management development, the aftereffects of this phenomenon are so powerful that its outcomes can very conveniently serve as an important instrument to study and bring remarkable changes in organizational behavior if properly implemented. Professional individuals today desire a sense of achievement which surpasses the monetary benefits or power positions at work. They now equally demand for inner-peace, mental satisfaction, emotional health and wellness as their employee right in the organization. This means that the people want to grow in terms of professional expertise, personal as well as in the spiritual sense. Long gone are those days when the working class could seldom make it to the social or esteem needs (third and fourth stages in the Maslow's need hierarchy pyramid). With the rapid force of time, people today at work are eager to reach their self-actualization needs even at early stages of work. The contemporary approaches for personal growth also advocate that the spirits and the sciences go hand and hand, for which the modern theories are trying to suggest connectivity between the 7 chakras for Spiritual growth with the Maslow's Need Hierarchy Pyramid and merging the eastern as well as the western philosophies together (Fig.3). ${ }^{[5]}$

\section{Western Psychology}

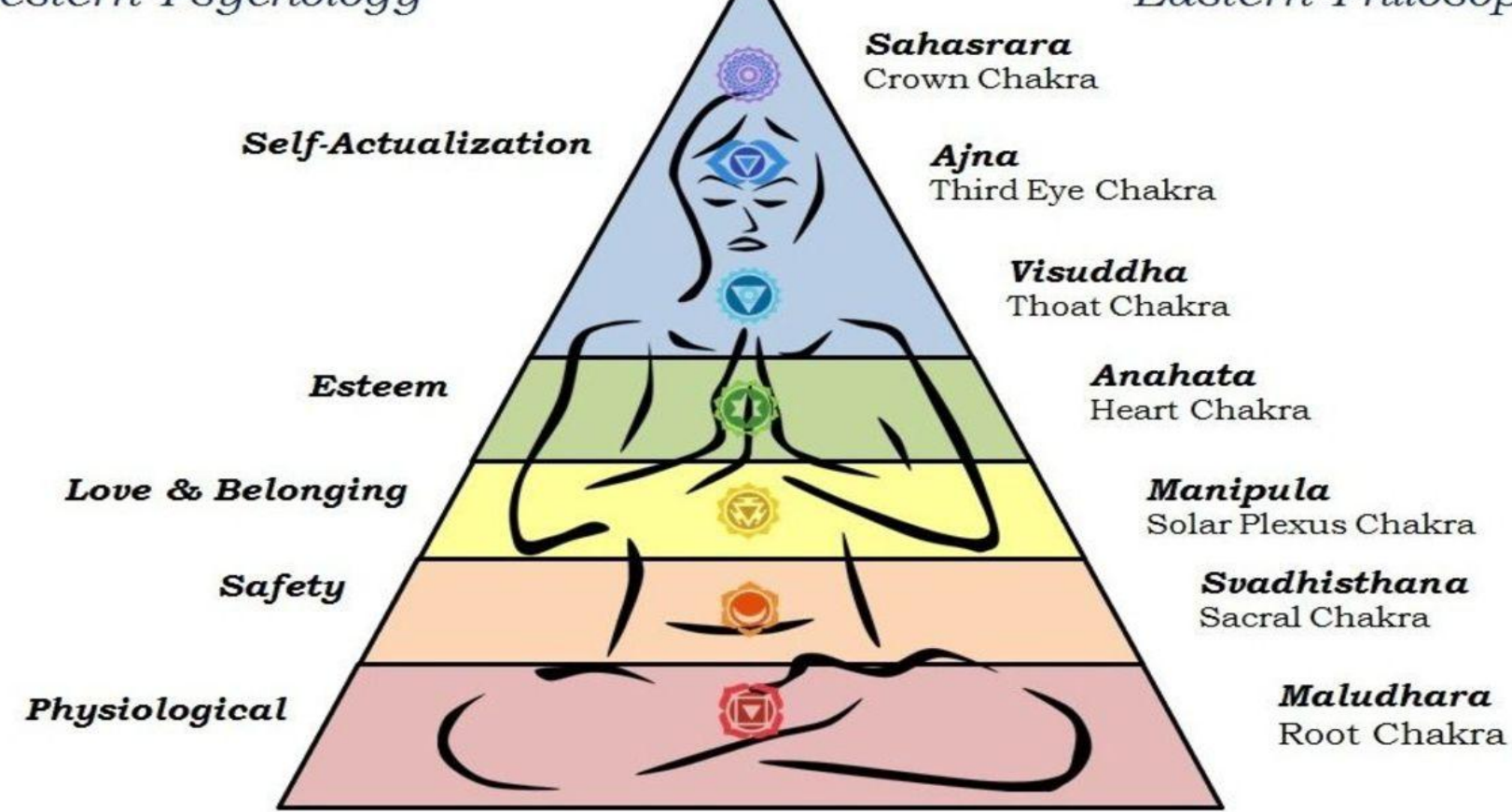

Figure 3. Maslow's Hierarchy v/s the 7 Chakras 
Workplace spirituality was introduced so that the compassionate individuals in distinct job roles could seek fulfillment in an organization by all means. For the same purpose, even the religious faiths of individuals at work are being combined with the management theories. Example:the self-actualization needs can also be attributed to the Fivefold ministry as per the Gospel and the stages of Spiritual growth in Christianity, providing a worthy traditional reference to align with the scientific studies of HR management(Fig. 4). ${ }^{[6]}$

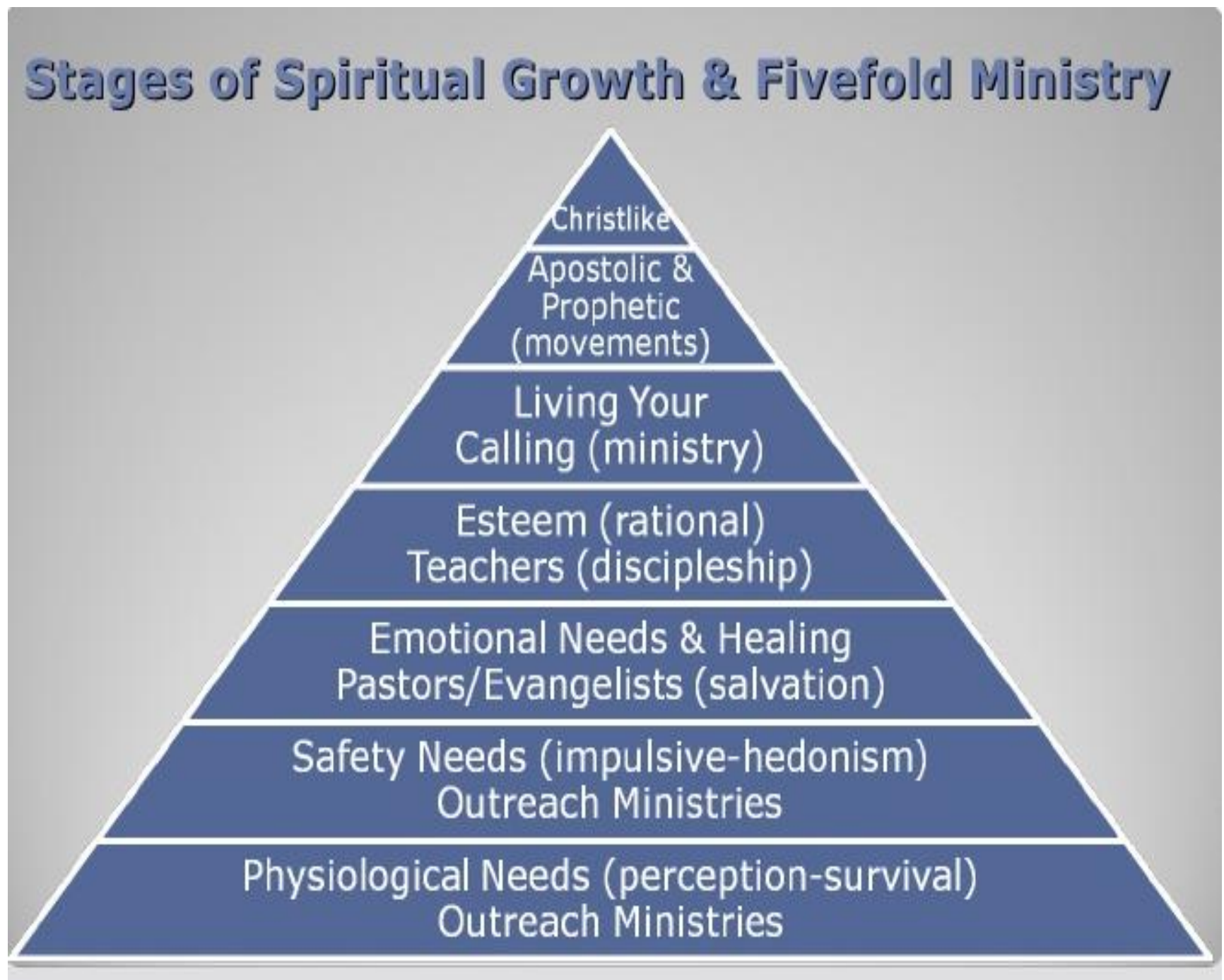

Figure 4. The Stages of Spiritual Growth

Workplace spirituality is an honest endeavor by the concerned management and the principal authorities to extend genuine care for their workforce, meanwhile nurturing them adequately as they grow, giving them a sense of completeness and bringing joy and delight in their regular office-tasks so give their best in whatever they are aspiring to achieve in the organization. In other words, workplace spirituality emphasizes on allowing the people to live and practice their beliefs, their faith and their principles in the workplace.

\section{SPIRITUALITY AND RELIGION}

Though religion and spirituality both talk of faith, principles and cosmic learning, there is a difference between the two if we ponder in depths (Fig. 5) ${ }^{[7]}$ Religion is man-made. It gives a definite set of principles to follow, definite God/Gods to preach and worship, fixed ways to perform rituals and even punishments for disobedience to the religious convictions. Contrary to this, spirituality empowers people to find their interconnection with their innerconscience first and then the supreme force (God). It talks about spirits and energies as integral part of the universe and promotes enquires, reasoning and logic, where a person can justify the path he has chosen to walk on.

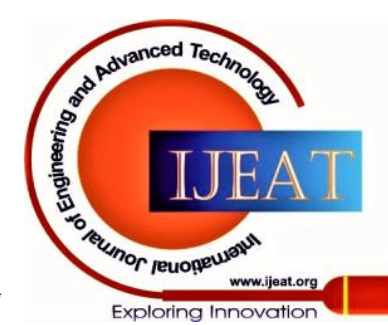




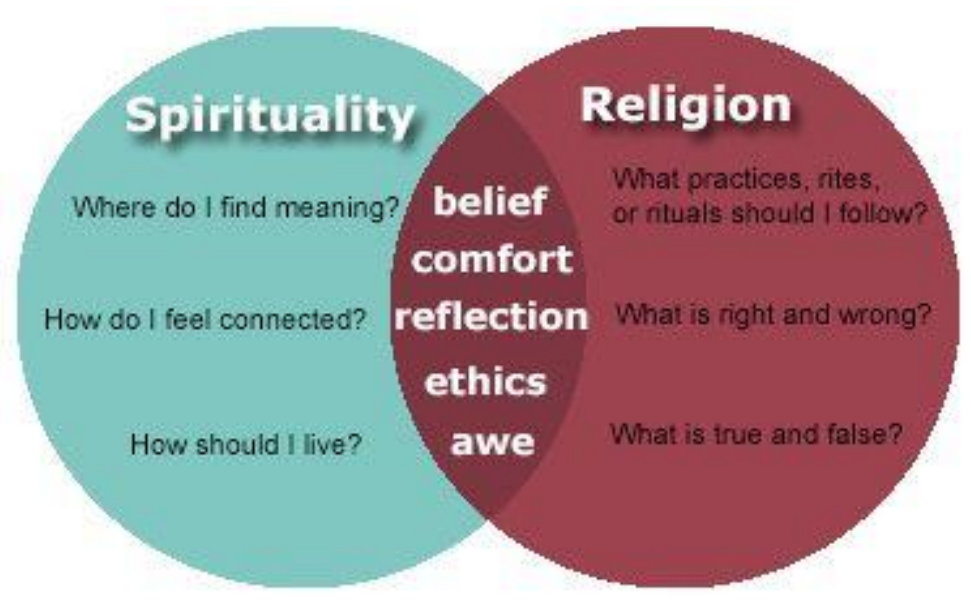

Figure 5. Spirituality and Religion: Similarities and differences

Religion focuses on religious teachings and mythology, learning from the experiences of others. Spirituality on the other hand is liberating. It asks an individual to draw his conclusions on basis of the experiences of his own. Religion renders instructions about the do's and the don'ts, whereas spirituality lets one decide about his own right and wrong. Religion divides the people on grounds of their religious faiths to build communities, but spirituality emphasizes on realizing and accepting the true nature of the spirit. It binds people enabling individuals to accept others just as how they are (along with their self-defined principles and innervalues) so that distinct souls can co-exist, sustain and grow together. Thus a person can be religious but not spiritual, spiritual but not religious, both or none. ${ }^{[8]}$ Yet whichever case a person may choose to lead his with and on whatever principles, discipline stands universal for all!

\section{URGENCY OF WORKPLACE SPIRITUALITY IN INDIA}

India has been a hub of Spiritual values and practices, giving rise to one of the most cherished treasures as a blessing to humanity - Yoga and Meditation. The country is a land of diverse religions and varied cultures, yet the constant has always been the spiritual belief of the masses and their faith in the supreme force. Hinduism in particular, has always stressed on the attainment of Nirvana as the ultimate goal of a spirit, over all worldly gains and material desires. As such the Hindu scriptures provide access to many spiritual texts and knowledge of the divine, revered by the learned scholars of the Vedic times and beyond. With almost majority of the Indian population recognizing themselves as Hindus, it becomes mandatory to lay stress on the inefficiency of the country to imbibe workplace spirituality, despite its rich spiritual heritage.
One of the primary reasons can be the lack of awareness and insight. In India, Spirituality was seldom seen as a matter of concern for the youth, though the trend today is changing. It was basically deemed as a healthy engagement for the old and the retired. However, in the western cultures, the adoption of spirituality was celebrated by individuals (working or not) at all levels and at different age-groups. Indians couldn't perceive the idea of clubbing their spiritual values with their work-policies simply because they couldn't particularly recognize it in any other form, than a means of cleansing the soul and attaining Moksha. But then there were countries like Japan, which gave due importance to Workplace Spirituality for training and developing their Human Resources in a manner that they can efficiently implement such techniques like 'just-in-time, Ringi method and multi-skilled work teams'. The phenomenon of Workplace spirituality across the world is spreading like a wild fire and Indian corporates will have to buck-up if they want to survive in the global market. The personal values of working individuals when aligned with their organizational values, lead to enhanced job performance and greater job satisfaction (Fig. 6). ${ }^{[9]}$ The job-satisfaction in the foreign countries is higher due as compared to India because they give importance to their spiritual values at work for their employee wellness. For this reason the Indian workforce (present or potential) wants to migrate abroad, leading to the problem of 'Brain Drain'. The inadequacy of the Indian organizational culture to practice spirituality at work and the cold attitude of the management towards Employee wellness, somewhere renders a very welcoming passage for issues like lower GDP, increased employee turn-over rates and pool of unsatisfied HR leading to lower productivity. This loop of is incompetence is fatal for the economic health and can be a matter of grave concern for the nation, hence needs to be addressed at its earliest!

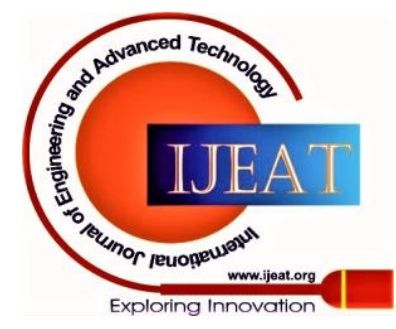




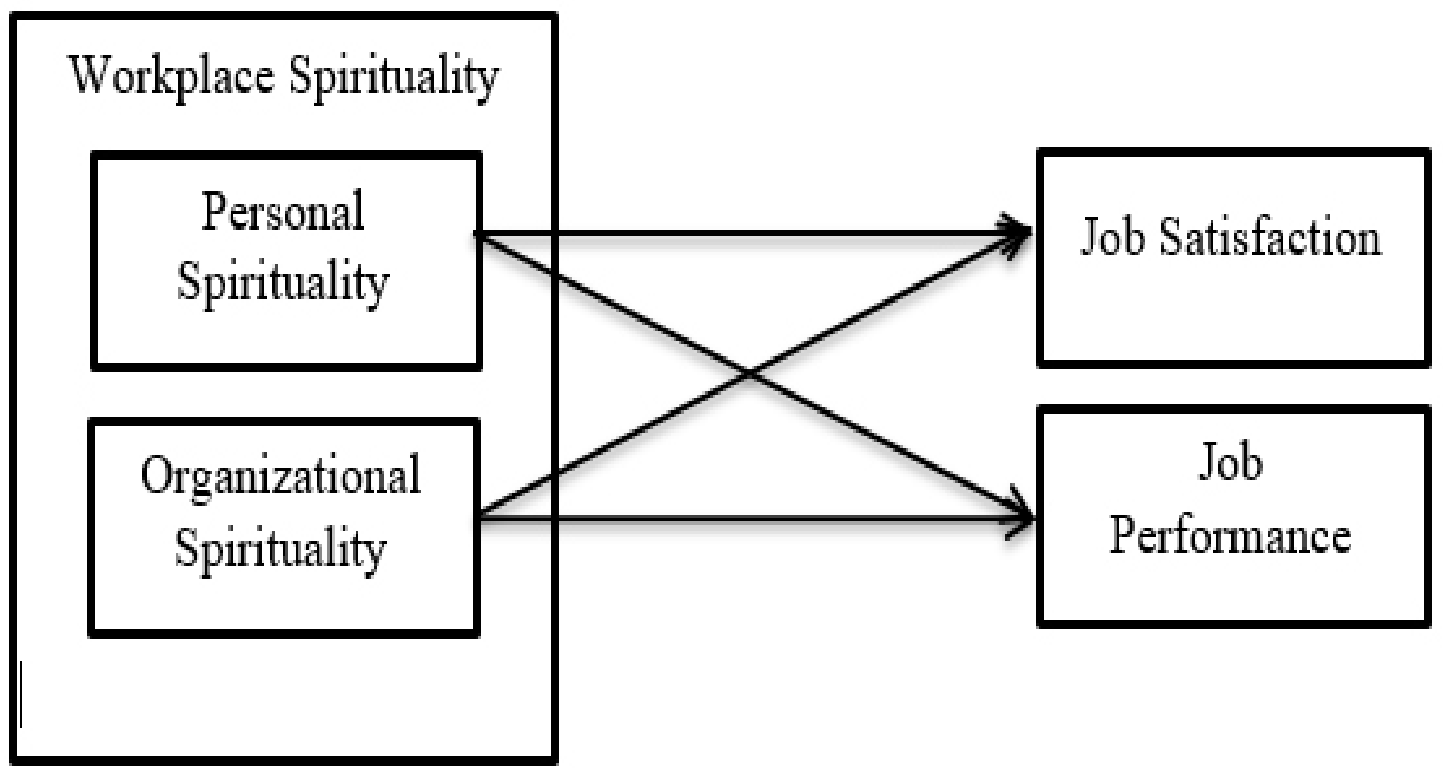

Figure 6. Impact of workplace spirituality on job satisfaction and job performance

1. Organizations reaping the good yields workplace spirituality (Foreign corporates and Global leaders followed by Indian giants and multinationals)

Various global and multinational firms have welcomed workplace spirituality into their corporate culture with wide open arms. Though adopted by the foreign organizations first, the movement is now constantly evolving in India as well. USA Today published a poll where $6 / 10$ of the total workforce believes that spirituality at work greatly impacts the work environment with positive outcomes. For this reason western companies are resorting to hire chaplains (a clergy man associated with the chapel) to guide and empower their workforce with regards to their spiritual beliefs. The Food giants like Coca-Cola, Pizza Hut and Tyson's Foods are topping the list in such practices. ${ }^{[10]}$ They provide spiritual consultancies to the distressed employees at work with the aid of the chaplains and their turnover rate has gone down by $50 \%$. In the similar manner, McKinsey, the global consultancy giant introduced meditation program for their employee wellbeing and was once even able to secure a business worth 20 million USD through a spiritual program designed for an Australian client. ${ }^{[10]}$ Southwest Airlines provide their air services at the lowest possible rates and are compassionately committed to delivery best customer experiences. ${ }^{[10]}$ They give the credits to their spiritual beliefs and values in their organization for keeping up their business. The world's biggest independent electrical power producer in Virginia, AES (Advanced Encryption Standard) corporation, contributes to the economic wellbeing of people throughout the globe by distributing electricity in a way that it leads to a greener energy future. ${ }^{[10]}$ Their noble ideas and honest endeavours are supported by their spiritual sense of serving the society.Other than this, companies like Hewlett-Packard, Wetherrill Associates, Tom's of Maine, The Men's Wearhouse etc. are also on the path of spirituality to develop and train the HR for increased and ethical performance. ${ }^{[10]}$

With the thunder striking news of the western firms bathing in the success stories of Workplace spirituality, the Indian Corporates felt compelled to introduce the phenomenon in their work-cultures. The management was inspired to induce spiritual practices in workplace andwitness the up-shots themselves. The IT leaders Wipro and Infosys can serve as very good example for ethical evolution in workplace for virtue building and fair conduct of their taskforce. ${ }^{[1]}$ The 'Corporate Executive Program' by ShriShri Ravi Shankar is also being promoted by Indian corporates to focus on desired moral conduct and ethical behavior at work, besides providing ways for individuals to deal with job-stress and gain peace and happiness while performing a given task in an organization. ${ }^{[1]}$ The market leaders and Indian multinationals like like Tata Tea, Excel Industries, Reckit and Coleman, Aarti International Ltd. and Daburare also imbibing the spiritual culture as a significant aspect of their work environment. ${ }^{[11]}$ Times of India is also taking active interest in nurturing spiritual reliance and optimism in their professional atmosphere. ${ }^{[11]}$

\section{WORKPLACE SPIRITUALITY - A TOOL FOR CONVERTING HUMAN RESOURCE TO HUMAN CAPITAL}

Workplace spirituality is an emerging theory for understanding work dynamics. It is evolving as an important tool for studying and analyzing the conduct of the human resources at work under the head of Organizational behavior as the core concept of HR Management. It helps in converting the human resources into human capital. The difference is, when the Human Resources are developed in such a manner that there is some value addition done to their set of KSA (Knowledge, Skills and Abilities), they become Human Capital. Human capital ascertains greater productivity and enhanced performance of the business, thereby proving to be the most important asset of an organization.

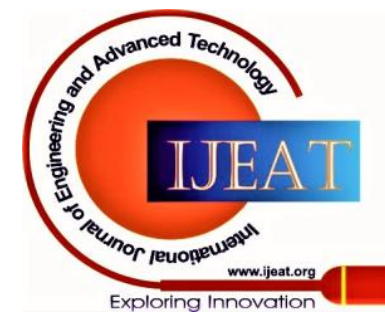


However, in India due the abundance of human labor and shortage of jobs, unemployment is inescapable. With people suffering hard to build a sustainable career, the working class is often taken for granted by the management. The demand for human resources is quite low as compared to the supply and hence is how the 'Hire and Fire' comes into play. The management seldom takes any appropriate measures to provide skill based trainings to the employees and spiritual wellness becomes a distant dream. The truth anyway points out that workplace spirituality lends a pivotal assistance in making an efficient use of the available human resource within an organization regardless of the demand and supply forces. This concept might seem a little complex but the cycle is relatively easy to comprehend. According to various researches conducted on national and international levels, Spirituality at work leads to a feeling of motivation, liberty, confidence, loyalty, trust, happiness and health in an organization. All these factors lead to a widely accepted term called "Employee Wellness" or "Employee wellbeing" (looking after the health and happiness of employees at psychological, social as well as spiritual well-being and Workplace spirituality shares a positive relationship with each of them. ${ }^{[12]}$ Now that the Employee wellness has a direct relationship with the Job Satisfaction and job satisfaction in turn is directly related to employee turnover, both these factors help in improving productivity. In other terms, spirituality at work leads to increased employee wellness, increased employee wellness leads to greater jobsatisfaction and greater job-satisfaction leads to reduced employee turnover and improved productivity. Thus, Workplace spirituality helps in retaining competent HR and taking care of the people at work while simultaneously promoting their growth on grounds of professional, personal and spiritual levels. The Indian corporates today must keep their doors open to allow the fresh talent into the work culture, but they must simultaneously be aware of the advantages that come with retaining experienced and committed stuff in the organization. They must do their best to engage in the professional, personal as well as spiritual wellness of their employees and help in developing their standard human resources into quality human capital. NOTE: Employ wellness is a program or a promotional activity which is designed by the organizations to improve and support healthy and ethical employee behaviour in their work environment. It is also associated with as corporate wellbeing or workplace wellness. It basically pertains to taking care of the people at work and treating them as a limb of the organization.

\section{WORKPLACE SPIRITUALITY BRINGS BETTER CORPORATE FORTUNE}

There are certain characteristics that differentiate the spiritual organizations from the non-spiritual ones, like employee empowerment, strong sense of purpose, tolerating employee expression, openness and trust. ${ }^{[13]}$ These characteristics mark various positive changes that can be observed if spiritual path is followed for professional work, meanwhile inviting possibilities of limitless growth.Workplace Spirituality hence brings good fortune for the organization in the sense that itnot only ensures fairness work). Employee wellbeing four dimensions i.e. emotional,

and justice in the organization, but also brings creativity, enthusiasm and delight in the work culture. It leads to significant meaningful transformations in the professional life of employees, thereby vividly benefiting the management, the organization as well as the customer base at large. The role of the HR department in this regard can be crucial.By taking care of the different aspects of the corporate environment and people's behavior at work, or simply by matching their inner values of individuals with the organization's overall moral conduct, better performance and productivity is promised. This in turn helps to foster better fortune for spiritual organizations as compared to the regular organizations which are yet to adoptthis evolving concept of workplace spirituality. Few of such factors paving a way for good fortune in the corporate culture are listed below:

\subsection{Maintaining dedicated workforce}

Commitment and dedication are important components of Spirituality. An organization where the management respects and gives independence to the employees for following their spiritual beliefs at work, reaps the benefits in terms of retaining and maintaining dedicated workforce. Loyalty along with diligence is willingly served to the organization on part of the employees.

\subsection{Enhanced Productivity}

Spirituality at work can be an effective tool for the management to increase employee productivity as well as the organizational efficiency. The management tends to attend to the social needs of the employees and makes a way for them to reach their self-actualization needs. When the people at work in such organizations witness a hope for their spiritual growth in their career prospects, they employ the best of their efforts into their work, leading to better output and increased productivity.

\subsection{Market reputation}

Spirituality brings ethical conduct and virtuous behavior in the employees. Organizations with undisturbed moral standing in the eyes of various stake holders in the market, specifically due to the practice of their spiritual norms, enjoy an increased goodwill and better reputation than the competitors. This renders an added advantage of attracting good crowd, investors and more clients from outside.

\subsection{Preventing frauds}

With a better sense of dos and don'ts, backed by the voice of the inner conscience, the Human resources at work think twice before committing any crime, misappropriations, manipulations or frauds in an organization. This reduces the possibility of loss and damage of any kind as well as promotes fidelity amongst the workforce towards the organization.

\subsection{Maintaining work/life balance}

Striking a balance between the family obligations as well as the professional relationships is important. Workplace spirituality ensures that the personal and family aspects of an individual's life are not consumed by work pressures. It helps a person to leave the work related issues at office desk only and have a gala time at home.

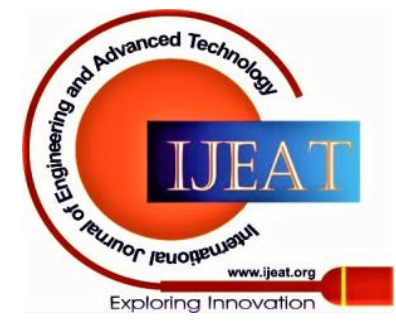




\subsection{Eliminating dullness and boredom}

Sometimes regular jobs become boring or dull due to lack of interest or creativity or due to any other professional or personal reasons. Spiritual practices at work help to expand the mental faculties of an individual, besides providing with an aid to retain focus. It hence helps in eliminating dullness and disinterest in various job roles.

\subsection{Improving learning experience}

A brilliant way for the management to develop, train and enable the employees to better handle the work contingencies in the dynamic environment, can be ensured by implementingworkplace spirituality in the organizational culture. It is about taking risks to open up one's spiritual self. For the overall growth of the employees, spiritual organizations do rational analysis of professional and dimensions at work and tend to give meaning to the job and the job roles of the respective workforce. This enhances their learning experience as they engage better.

\subsection{Team work and Harmony}

Eliminating unnecessary strictness, unhealthy competition and unjustified criticism in a workplace can be done away with, when the management seeks to embrace a spiritual culture in an organization where individuals work together as a team in harmony and understand, inspire, appreciate, support and encourage the work ethics of management and co-workers. It also helps in establishing trust, honesty and openness.

\subsection{Mental peace and stress management}

Spiritual practices at work like light breathing, positive listening, meditating and effective communication can help a working individual deal with regular office stress and help in sustaining mental peace. The calm of a person is restored and heavily assigned tasks become easier to tackle.

\subsection{Building confidence}

Spirituality allows the people at work to determine their own right and wrong and evaluate the pros and cons according to their understanding of good and bad. This helps them to make better choices and building their confidence, preparing them as future leaders.

\section{IMPLEMENTING WORKPLACE SPIRITUALITY}

The psychological as well as physical dimensions of people at work were extensively studied, neglecting the spiritual aspects of work life of an individual for many years. But now that the context is being equally observed in the professional light, it becomes significant to understand that the good yield of Workplace spirituality can only be reaped when the phenomenon is properly and rightfully implemented in the organization. Dr. Mark J.Titi (allergistimmunologist, Pennsylvania) gave 5 ways of integrating Spirituality into the workplace - Start by connecting with your values, be the example, figure out what's important for your coworkers, take a gifts inventory and take action, create a work environment that fosters spirituality. ${ }^{[14]}$ However, some otheralternatives of effectively implementing Workplace Spirituality are given below:

\subsection{Conducting mindfulness programs}

Mindfulness implies to a state of mind where a person is aware of self and the surroundings, with a better sense of what is actually going on in a particular moment, there and then. It expands the mental faculties, creativity and ability to understand and grasp things more proficiently in a person. Mindfulness is an excellent way to induce spiritual values in the work culture of an organization through meditations, recreational trainings and yoga. It helps you to attend to the calling of the soul by concentrating on your thoughts, emotions, feelings and sensations, thus living every bit of each moment spent alive.

\subsection{Accepting Diversity}

Workforce diversity in an organization is a common phenomenon today. People from various backgrounds work together to meet personal and organizational goals and objectives. However, all these individuals carry their unique identity and spiritual values. As such, one's moral principles and ideologies may not always align with another's. Their faith and practices may not be similar. Thus management must ensure that 'acceptance' is inculcated in the work culture, so that different people are able to accept different ideas and ways of performing a particular job, hence working in consensus.

\subsection{Creating liberal work-environment}

According to the management principles, authority, responsibility and accountability are interlinked. When a job is assigned to the employees and some responsibility is levied on their shoulders by the senior management, then the required amount of authority on how to perform the job and take related decisions must also be delegated to them. It is only then that the employees feel accountable for their job roles and approve of their answerability to the management in case of below standard performance. Thus a liberal environment where employees are motivated to analyze and take decisions about work, based on their professional knowledge and spiritual understanding, always helps in building responsible and reliable HR.

\subsection{Ethical training}

Apart from the regular organizational policies and procedures, management must take initiative to educate and train their employees about the ethical code of conduct in a workplace. There are certain set of rules which are deemed a mandate as per the organizational norms, but then there are another set of moral values which may not be found on any piece ofan official document, a board notice or an employee circular. The employees must be well equipped with such inherent principles so they can carry out their work in an ethical manner and trainings to provide for the same must be taken by the management and concerned authorities.

\subsection{Self-space at work}

This is a concept where in the workforce is allowed to take some time off their regular job roles and spend some time with themselves by undertaking activities that make them feel connected to themselves, builds their creativity and interests in the jobs assigned to them as well as enables them to enjoy and experience happiness at work. 
The work pressure must be reduced so that employees can get a chance to question, reason and think whatever assignments and tasks they are undertaking in an organization. No professional authority must introduce in their self-space rather take measures to promote the beautiful pursuit of introspection and self-learning.

\section{CONCLUSION}

Workplace spirituality has been called 'The essence of Modern Organizations' because it renders an effective tool to handle stress related issues and overcome business problems, like business losses, strained relationships with customers, delayed contracts and employee exitsetc. ${ }^{[15]}$ Also, there are many positive elements of work-life on which spiritual values are based (for instance - ethics, motivation, morals, leadership and work/life balance) and all these attributes are identified as the essential traits for maintaining a healthy corporate-environment. The management solicitsvarious spiritual approaches for shaping the modern organizations, thus helping the employees with personal disorders and other work-related problems. ${ }^{[15]}$

Though Workplace spirituality is a budding concept of Human Resource Management in India, but its pay-offs are compelling for both, the management as well as the organization. It is evolving at a global level on such massive grounds that it is now seen as a pervasive cure to fill all the gaps in management philosophy. India is in dire need to embed spirituality in work culture not just to level up its global trade-play, but also to eliminate its major drawbacks related to various economic issues like retaining competent personnel, decreasing productivity, lesser growth prospects for the employees, increased migration etc. and help address these subjects of grave concern for the nation to a large extent. There is an exigency to acknowledge the worth of the HR and initiate steps for the personal, professional as well as spiritual developmentof the employees, so that wealth and prosperity can be achieved by the Indian Corporates at the same time.

\section{REFERENCES}

1. PravinAgarwal; Speaking Tree: The Four Ages of Man - The 4 Stages of Life in Hinduism; (October 24, 2015) https://www.speakingtree.in/blog/the-four-ages-of-man-the-4-stagesof-life-in-hinduism

2. The Economic Times: Tagore, Satyarthi And 8 Other Nobel Winners Who Have Made India Proud;(October 19, 2019) https://economictimes.indiatimes.com/magazines/panache/tagoresatyarthi-and-8-other-nobel-prize-winners-who-made-india-proud/theindian-connection/slideshow/71629526.cms

3. Bryn Dodd Centers for Children and Families; MRT: 'Wellness wheel' can provide a balanced life; (August 30, 2017) https://www.mrt.com/news/health_and_wellness/article/Wellnesswheel-can-provide-a-balanced-life-12159559.php

4. Be Still Ministries: The Six Basic Principles of Spirituality; (March 7, 2017) https://bailiesdevotions.weebly.com/devotions/the-six-basicprinciples-of-spirituality

5. Dr. Diane Roberts Stoler; Psychology Today: Maslow's Hierachy vs. 7 Chakras- Interestingly Similar!Could blending Eastern Philosophy and Western Psychology be the key to success?; (April 15, 2018) brain/201804/maslows-hierachy-vs-7-chakras-interestingly-similar

6. Andrew Sears: TechMission (www.techmission.org): Introduction to systemic theology

https://www.slideserve.com/xue/introduction-to-systemic-theology https://www.psychologytoday.com/gb/blog/the-resilient-

7. AkhilAneelDeshpande, AnujDeshpande and Swati Joshi; ResearchGate: E-learning as A Tool inBridging the Gap Between Engineering and Spiritual Learning (December, 2016) https://www.researchgate.net/publication/312024210_Elearning_as_A _Tool_inBridging_the_Gap_Between_Engineering_and_Spiritual_Le arning

8. Dr. Josh Gressel; Psychology Today: Are You Spiritual or Religious? Does it Matter?Where you fall on the spiritual/religious continuum; (October 4,2015)

https://www.psychologytoday.com/us/blog/putting-psyche-backpsychotherapy/201510/are-you-spiritual-or-religious-does-it-matter

9. Muhammad AsimFaheem; Muslim Perspectives Journal (Volume 2; Issue 1): Role of Workplace Spirituality in Achieving the High Job Performance and Job Satisfaction: Employees of Social Welfare Organizations of Pakistan (2017) https://www.muslim-perspectives.com/Publication-

Detail?publication=24/Role-of-Workplace-Spirituality-in-Achievingthe-High-Job-Performance-and-Job-Satisfaction:-Employees-ofSocial-Welfare-Organizations-of-Pakistan

10. Dr. RitikaShrivastava; PeopleMatters: Spirituality and Workplace; (February 22, 2017)

https://www.peoplematters.in/article/life-at-work/spirituality-andworkplace-14997

11. GradesFixer: Workplace Spirituality In India(2019, August, 27) https://gradesfixer.com/free-essay-examples/workplace-spiritualityin-

india/\#: :text=Apart $\% 20$ from $\% 20 \mathrm{it} \% 20 \mathrm{Companies} \% 20$ such,Spiritual ity\%20is\%20a\%20budding\%20concept.

12. Badrinarayan Shankar Pawar;Emerald Insight:Workplace spirituality and employee well-being: an empirical examination; (October 3,2016) https://www.emerald.com/insight/content/doi/10.1108/ER-11-2015$\underline{0215 / \text { full/html }}$

13. Dr. LalatenduKesari Jena; People Matters: Is there a room for spirituality at our workplace?; (February 15, 2019) https://www.peoplemattersglobal.com/site/interstitial?return to $=\% 2 \mathrm{~F}$ article\%2Flife-at-work\%2Fis-there-room-for-spirituality-at-ourworkplace-20839

14. MarkTiti; Addicted2Success (Success Advice): 5 Ways to integrate Spirituality into the Workplace; (June 18, 2016) https://addicted2success.com/success-advice/5-ways-to-integratespirituality-into-the-workplace/

15. Moitreyee Paul and PurnaSaha; ResearchGate: Workplace Spirituality-The Essence of Modern Business Organizations; (January 2015)

https://www.researchgate.net/publication/282784719_Workplace_Spi rituality-

The Essence of Modern Business Organizations\#: :text=Workplac e\%20Spirituality\%E2\%80\%93The\%20Essence $\% 20$ of $\% 20$ Modern $\% 2$ 0Business\%20Organizations,-

Article\%20(PDF\%20Available \&text=Previously $\% 2 \mathrm{C} \% 20$ workplace \%20was\%20depicted\%20as,of\%20task\%20accomplishment \%20were \%20paramount.\&text=Spirituality \%20draws\%20on \%20the\%20ethics ,leadership\%20elements\%20of\%20an\%20organization.

16. Ashmos, P. D., \&Duchon, D. (2000). Spirituality at work. Journal of Management Inquiry. 92. 134-145. http://dx.doi.org/10.1177/105649260092008

17. Brown, R. B. (2003). Organizational spirituality: The skeptic's version. Organization. 102. 393-400. http://dx.doi.org/10.1177/1350508403010002013

18. Burack, E. H. (1999). Spirituality in the workplace. Journal of Organizational Change Management. 124. 280-291.

http://dx.doi.org/10.1108/09534819910282126

19. Daniels, D., Franz, R., \& Wong, K. (2000). A classroom with a worldview: Making spiritual assumptions explicit in management education. Journal of Management Education. 245. 540-561. http://dx.doi.org/10.1177/105256290002400503

20. Daniel, J. L. (2010). The effect of workplace spirituality on team effectiveness. Journal of Management Development. 295. 442-456. http://dx.doi.org/10.1108/02621711011039213

21. Delbecq, A. (2000). Spirituality for business leadership. Journal of Management Inquiry. 92. 114-132. http://dx.doi.org/10.1177/105649260092005

22. Duchon, D., \& Plowman, D. A. (2005). Nurturing the spirit at work: Impact on work unit performance. Leadership Quarterly. 165. 807815 . 
http://dx.doi.org/10.1016/j.leaqua.2005.07.008

23. Ebaugh, H. R. (2002). Return of the sacred: Reintegrating religion in the social sciences. Journal for the Scientific Study. 413. 385-395. http://dx.doi.org/10.1111/1468-5906.00125

24. Emblen, J. D. (1992). Religion and spirituality defined according to current use in nursing literature. Journal of Professional Nursing. 81. 41-47.

http://dx.doi.org/10.1016/8755-7223(92)90116-G

25. Fernando, M., \& Jackson, B. (2006). The influence of religion-based workplace spirituality on business leaders' decision-making: An interfaith study. Journal of Management and Organization. 121. 23-39. http://dx.doi.org/10.5172/jmo.2006.12.1.23

26. Freshman, B. (1999). An exploratory analysis of definitions and applications of spirituality in the workplace. Journal of Organizational Change Management. 124. 318-327. http://dx.doi.org/10.1108/09534819910282153

27. Harrington, W. J., Preziosi, R. C., \& Gooden, D. G. (2001) Perceptions of workplace spirituality among professionals and executives. Employee Responsibilities and Rights Journal. 133. 155165. http://dx.doi.org/10.1023/A:1014966901725

28. Howard, S. (2002). A spiritual perspective on learning in the workplace. Journal of Managerial Psychology. 173. 230-242. http://dx.doi.org/10.1108/02683940210423132

29. Jurkiewicz, C. L., \&Giacalone, R. A. (2004). A values framework for measuring the impact of workplace spirituality on organizational performance. Journal of Business Ethics. 492. 129-135. http://dx.doi.org/10.1023/B:BUSI.0000015843.22195.b9

30. Ketchand, A. A., \&Strawser, J. R. (2001). Multiple dimensions of organizational commitment: Implications for future accounting research. Behavioral Research in Accounting. 13. 221-251. http://dx.doi.org/10.2308/bria.2001.13.1.221 